\title{
Cytodiagnosis in the management of extrahepatic biliary stricture
}

\author{
L A Desa, A B Akosa, S Lazzara, P Domizio, T Krausz, I S Benjamin
}

\begin{abstract}
A total of 117 patients presenting with extrahepatic biliary strictures between 1981 and 1989 had 206 cytological examinations of the bile duct or bile (153 non-operative, 53 intraoperative) to establish the presence of malignancy. A final diagnosis of cholangiocarcinoma was made in 88 patients, with 29 patients having benign biliary strictures. The cytological techniques used were fine needle aspiration $(n=102)$ or brushing $(n=24)$ of the bile duct, or exfoliative cytology of bile $(n=80)$. Forty one patients with malignancy had two or more examinations with differing results between samples in 20 cases. The overall sensitivity was $72 \%$. There was only one false positive result, giving a patient predictive value of positive cytology of $98 \%$. Intraoperative cytology was more sensitive than nonoperative examination $(80 \% v 42 \%)$. Overall, the sensitivity of fine needle aspiration $(67 \%)$ was greater than that of brush cytology $(40 \%)$ or exfoliative cytology (30\%). No complications were encountered. Cytodiagnosis of extrahepatic biliary strictures is a safe procedure which is not technically demanding, and as it has a high sensitivity and predictive value for positive cytology, cytological confirmation of malignancy should be sought in all clinically and radiologically suspicious cases.
\end{abstract}

Cholangiocarcinoma must always be considered in the differential diagnosis of extrahepatic biliary strictures. The increasing range of treatment options available has increased the importance of a preoperative diagnosis of malignancy in planning further management. Cytological techniques have played an important part in the clinical management of patients with intraabdominal malignancies. '2 Their use in extrahepatic cholangiocarcinoma, however, has been infrequently documented..$^{3-7}$

We report our nine year experience (1981-9) with cytological techniques in the diagnosis of malignant extrahepatic biliary strictures.

\section{Methods}

Altogether, 117 patients with extrahepatic biliary strictures had 206 cytological examinations of the bile duct or bile. There were 66 male and 51 female patients, ages ranging from 21 to 85 years (median 58 years). Samples were obtained preoperatively, intraoperatively, or in the postoperative or poststenting periods. Five patients with benign disease had samples taken in the postoperative period, because of uncertainty about the diagnosis of malignancy despite histological evidence of a benign lesion, while 10 patients with malignant disease who did not undergo surgery had samples taken repeatedly after insertion of stents to obtain cytological proof of malignancy. Non-operative fine needle aspirates were obtained from the stricture with the help of sonographic guidance or fluoroscopic guidance at the time of contrast cholangiography. Exfoliated cells from bile were obtained at the time of percutaneous transhepatic cholangiography and 24 hours after biliary drainage had been instituted. Brushings from the papilla or lower common bile duct were obtained at endoscopic retrograde cholangiopancreatography or at laparotomy.

A final diagnosis of cholangiocarcinoma was made in 88 patients, while 29 patients had benign biliary strictures. In 38 patients the diagnosis of cholangiocarcinoma was confirmed histologically. In the remaining 50 patients the diagnosis was based on the results of other investigations (ultrasound computed tomography, angiography, or cholangiography) and on the subsequent clinical course.

Aspirates were obtained by introducing a $9 \mathrm{~cm}$ 22 gauge spinal needle connected to a $20 \mathrm{ml}$ syringe into the area of the stricture, after accurate localisation, and applying suction while oscillating the needle for a few millimetres in its long axis within the lesion. At least two passes were made on each patient. Specimens were handled immediately by a cytology technician. Fine needle aspiration specimens were expressed onto glass slides and bile and cytology brushings were smeared directly on to slides. The slides were either fixed immediately in $95 \%$ alcohol solution and later stained by the Papanicolaou method or air dried and stained with the MayGrünwald-Giemsa stain. The syringe was then rinsed with Eagle's medium, centrifuged, and cytospin preparations made. Some smears were stained with the periodic acid-Schiff reagent with and without diastase digestion to identify mucin production. The slides were examined by two trained pathologists and coded as unsatisfactory (acellular), negative, highly suspicious for malignancy, or definitely positive.

The criteria for assessment of cytology from the biliary tract will be presented in detail in a 
TABLE I Sensitivity of techniques excluding 'suspicious for malignancy' cytology

\begin{tabular}{lllll}
\hline & & \multicolumn{3}{c}{ Cytology result } \\
\cline { 2 - 4 } Technique & $\begin{array}{l}\text { No of } \\
\text { specimens }\end{array}$ & $\begin{array}{l}\text { True } \\
\text { positive }\end{array}$ & $\begin{array}{l}\text { False } \\
\text { negative }\end{array}$ & $\begin{array}{l}\text { Sensitivity } \\
(\%)\end{array}$ \\
\hline Fine needle aspirate & 80 & 49 & 31 & $61 \cdot 3$ \\
Exfoliative cytology & 55 & 10 & 45 & $18 \cdot 2$ \\
Brush cytology & 10 & 5 & 5 & 50 \\
\hline
\end{tabular}

separate report (Akosa et al, in preparation). In summary, however, the main criterion for a negative cytological report was the observation of sheets of normal epithelial cells with bland nuclei in a mosaic pattern. A highly suspicious report was issued when a few, mostly individual, atypical cells were seen which were larger than normal, having a large nucleus with or without prominent nucleoli. A positive cytological result was reported when clumps and individual cells were observed with variable size and shape, an increased nuclear to cytoplasmic ratio, a thickened nuclear membrane, irregular chromatin pattern, and prominent nucleoli. Results were classified as true positive when a cytological positive or highly suspicious result was matched against a patient with either a histologically or clinically proved cholangiocarcinoma. A false positive result was one where a positive diagnosis of malignancy was made in a patient with a benign disease. Similarly, a false negative resulted from negative cytological smears in a patient with proved cholangiocarcinoma. A true negative result was obtained when a patient with benign disease had a negative cytology report.

Sensitivity is defined as true positive/true positive + false negative. A patient predictive value for positivity (PVP) was calculated by the formula $\mathrm{PVP}=$ true positive/true positive + false positive, while the predictive value for negativity (PVN) was PVN=true negative/true negative+ false negative. Statistical analysis was carried out using the $\chi^{2}$ test with Yates's modification.

\section{Results}

None of the patients suffered from any complications related to the procedure. Of the 206 samples obtained, fine needle aspiration of the common bile duct accounted for 102, exfoliative cytology of bile for 80 , and brush cytology of the papilla or lower common duct for 24 samples. There were 153 non-operative and 53 operative samples. The 88 patients with cholangiocarcinoma had 145 samples reported as either cytologically positive or negative for malignancy, and 23 as 'suspicious.' If the suspicious reports are excluded from analysis the differing sensitivities for the various techniques are as shown in Table

TABLE II Overall sensitivities of the various techniques (Numbers of unsatisfactory samples in parentheses)

\begin{tabular}{llllllll}
\hline & \multicolumn{2}{l}{ Cytology positive } & & \multicolumn{2}{l}{ Cytology negative } & \\
\cline { 2 - 3 } Technique & True & False & & False & True & \\
positive & positive & & negative & negative & $(\%)$ \\
\hline Fine needle aspirate $(\mathrm{n}=102)$ & 62 & - & & $31(4)$ & 9 & 67 \\
Exfoliative cytology $(\mathrm{n}=80)$ & 19 & - & & $45(21)$ & 16 & 30 \\
Brush cytology $(\mathrm{n}=24)$ & 5 & 1 & & $5(0)$ & 13 & 50 \\
\hline
\end{tabular}

I. Fine needle aspiration had a sensitivity of $61.3 \%$, which was greater than the $50 \%$ sensitivity for brush cytology. Exfoliative cytology had the least sensitivity of $18 \cdot 2 \%$. Of the 17 patients who had 23 samples reported as highly suspicious, 16 were diagnosed as having cholangiocarcinoma, the remaining patient having documented benign disease.

\section{CASE REPORT}

A 39 year old woman presented with progressively worsening jaundice three years after cholecystectomy. The results of the preoperative investigations showed a stricture of the mid to lower third of the bile duct. This stricture was excised at operation and a hepaticojejunostomy performed, leaving the last $2 \mathrm{~cm}$ of common bile duct in its intrapancreatic portion. Intraoperative brushings of the residual duct stump were reported as 'highly suggestive' for malignancy. She made an uneventful recovery and histology of the resected duct showed only reactive fibrosis and hyperplasia of the duct. Subsequent postoperative endoscopic brushings of the distal bile duct stump via the papilla on three occasions all showed normal epithelial cells, no mass was present on scanning, and a normal appearance of the residual duct was obtained on endoscopic cholangiography. She remains well after four years of follow up.

Thus suspicious reports were, with one exception, associated with malignant disease. We therefore feel justified in our decision to count suspicious reports as true positive when calculating the overall sensitivities of the various techniques. These sensitivities, including suspicious reports in the positive cytology group, are shown in Table II. The low sensitivity of exfoliative cytology was due to the high percentage $(47 \%)$ of unsatisfactory samples obtained (21/45 samples). In contrast, the percentage of unsatisfactory samples using fine needle aspiration was only $15 \%$. The remaining negative samples were all satisfactory with an adequate representation of benign epithelial cells. Intraoperative cytological examination was far more sensitive than the nonoperative technique in the diagnosis of malignancy $(80 \% v 42 \%$; Table III).

Forty one patients with malignancy had two or more samples taken for cytological confirmation. Despite repeated sampling, 20 patients had differing cytological reports, with 13 patients having persistently negative reports (Table IV).

Sixty three of the 88 patients with cholangiocarcinoma had at least one positive cytological report, thus yielding a sensitivity of $72 \%$. There was one false positive (suspicious) result in a patient with documented benign disease (see case report above). Thus the patient predictive value of positive cytology was $98 \%$, whereas that of negative cytology was $53 \%$.

\section{Discussion}

Fine needle aspiration biopsy is an important tool in the investigation of patients with hepatopancreatobiliary tumours. ${ }^{1-38}$ A positive cytological report for malignancy is especially 
TABLE III Comparison of non-operative and intraoperative cytodiagnosis in 88 patients with malignant strictures (Total number of specimens in parentheses)

\begin{tabular}{lll}
\hline & \multicolumn{2}{l}{ Positive cytology } \\
\cline { 2 - 3 } Technique & Intraoperative & Non-operative \\
\hline Fine needle aspirate & $28(31)$ & $34(62)$ \\
Exfoliative cytology & $4(8)$ & $15(56)$ \\
Brush cytology & $1(2)$ & $4(8)$ \\
Total & $33(41)$ & $53(126)^{\star}$ \\
\hline
\end{tabular}

${ }^{\star} \chi^{2}$ test $16 \cdot 779, p<0 \cdot 01$.

TABLE IV Differing cytological reports in 41 patients with multiple samples

\begin{tabular}{|c|c|c|c|}
\hline \multirow[b]{2}{*}{$\begin{array}{l}\text { No of } \\
\text { samples }\end{array}$} & \multicolumn{3}{|l|}{ No of patients } \\
\hline & $\begin{array}{l}\text { Matching } \\
\text { negative report }\end{array}$ & $\begin{array}{l}\text { Matching } \\
\text { positive report }\end{array}$ & $\begin{array}{l}\text { Mismatch: both } \\
\text { negative and positive } \\
\text { reports }\end{array}$ \\
\hline $\begin{aligned} & 2-3 \\
& 4-5 \\
> & 6\end{aligned}$ & $\begin{array}{r}11 \\
1 \\
1\end{array}$ & $\begin{array}{l}7 \\
\overline{1}\end{array}$ & $\begin{array}{r}15 \\
5 \\
-\end{array}$ \\
\hline
\end{tabular}

important in the management of extrahepatic biliary strictures, as both benign non-traumatic inflammatory strictures ${ }^{9}$ and isolated hilar strictures representing localised forms of sclerosing cholangitis $^{10}$ have been confidently diagnosed preoperatively as malignant strictures on the basis of radiological investigations alone. In such cases palliative forms of treatment, including radiotherapy, may be mistakenly used in the management of benign strictures on the basis of a radiological diagnosis of malignancy. This could explain the long survival of some patients with 'malignant' biliary strictures, after stenting and radiotherapy, in whom no histological or cytological confirmation of malignancy was made."

Cholangiocarcinoma is notoriously difficult to diagnose cytologically and our patient overall sensitivity rate of $72 \%$ is comparable to those reported (Table V). ${ }^{3-7}$ The causes for this high failure rate can usually be attributed to sampling errors due to the small size of these tumours and reliance on duct strictures at cholangiography to indicate the site of the tumour mass, and to cytological failures due to the high degree of differentiation of many bile duct tumours. ${ }^{3}$

We use a combination of fluoroscopic assistance at cholangiography and ultrasound guidance for aspiration. In a large series of pancreatic and bile duct aspiration biopsies, Hall-Craggs and Lees ${ }^{3}$ showed that combined sonographic and fluoroscopic biopsy guidance

TABLE V Data on sensitivity and biopsy guidance technique for bile duct cancers from reported series

\begin{tabular}{|c|c|c|c|}
\hline Reference & $\begin{array}{l}\text { No of } \\
\text { patients }\end{array}$ & $\begin{array}{l}\text { Sensitivity } \\
(\%)\end{array}$ & Guidance technique \\
\hline Hall-Craggs and Lees ${ }^{3}$ & 32 & 57 & $\begin{array}{l}\text { Ultrasound, percutaneous transhepatic } \\
\text { cholangiogram }\end{array}$ \\
\hline Cohan et al & 13 & 92 & $\begin{array}{l}\text { Ultrasound/computed tomography, } \\
\text { percutaneous transhepatic cholangiogram, } \\
\text { transcatheter biopsy }\end{array}$ \\
\hline Evander $e t a l^{\circ}$ & 19 & 53 & Angiography, percutaneous transhepatic \\
\hline $\begin{array}{l}\text { Kuroda et } a l^{s} \\
\text { Cope } e t a l^{+} \\
\text {Present series }\end{array}$ & $\begin{array}{l}14 \\
\text { Not specified }\end{array}$ & $\begin{array}{l}71 \\
60 \\
72\end{array}$ & $\begin{array}{l}\text { Transcatheter biopsy } \\
\text { Transcatheter biopsy } \\
\text { Ultrasound, percutaneous transhepatic } \\
\text { cholangiogram, endoscopic retrograde } \\
\text { cholangiopancreatogram, operative }\end{array}$ \\
\hline
\end{tabular}

with opacification of the bile or pancreatic duct resulted in a higher sensitivity rate than using sonographic guidance alone for the biopsies. We have used brush cytology both at the time of endoscopic retrograde cholangiography and at laparotomy. Endoscopic retrograde brush cytology of the biliary ducts, endoscopic scraping biopsies of malignant biliary strictures, and percutaneous brush biopsies of the biliary tree through an endoprosthesis have been described. ${ }^{12-1+}$ The initial promise of greater sensitivity using the transcatheter technique for aspiration biopsy has not been fulfilled - this is probably because many cholangiocarcinomas are densely sclerotic tumours, with relatively low cellularity and may show extraordinarily good differentiation morphologically.

All our cytological failures were due either to unsatisfactory (acellular) samples or to sampling errors, satisfactory material being obtained from the vicinity of the tumour. Fine needle aspiration had the highest sensitivity $(67 \%)$ of all the techniques in our series. Our $30 \%$ sensitivity rate for exfoliative cytology is disappointing and largely contributing to this high false negative rate was the large percentage $(47 \%)$ of unsatisfactory (acellular) samples. If these samples were disregarded the sensitivity of exfoliative cytology would be $44 \%$ (19/43). These bile samples were prepared by directly smearing the fluid on to slides, and centrifugation followed by smearing of the sediment might have resulted in a higher percentage of positive results. In our series only $15 \%$ of the false negative results using aspiration were due to unsatisfactory samples, which is commendable considering the small size of most of the tumours.

Our results confirm the observation by Soreide $e t a l^{15}$ that intraoperative cytology is more sensitive than preoperative cytology. The sensitivities of all three techniques increased dramatically when performed operatively, with exfoliative cytology achieving a sensitivity of $50 \%$. This is probably a reflection of the shedding of tumour cells into bile during operative manipulation and raises the possibility of manipulating the drainage catheter during percutaneous cholangiography to increase the tumour cell yield in bile. Indeed, Muro et $a l^{16}$ have shown that the sensitivity of bile cytology is higher after internal drainage than external drainage, which was attributed to local trauma, resulting from successful negotiation of the stricture by the catheter, increasing the recovery of exfoliated malignant cells.

We believe that a cytological diagnosis of 'suspicious for malignancy' should be counted as a positive result. Only one of our patients so coded had benign disease. The distinction between negative and suspicious reports is crucial and dependent on the presence of atypical cells. Only after careful deliberation should a report be labelled 'highly suspicious' in the presence of benign disease, as this has serious therapeutic implications. A cytological result reported as 'atypical' or 'suspicious' was considered negative in the series of Cohan et al, ${ }^{7}$ yet in no case did a patient with such a result have a benign disease.

There was only one false positive result in our 
series. This fallacy has been noted in a large series of fine needle biopsies of the pancreas. ${ }^{15}$ Though there has been no documented report of a false positive cytological result in biliary cytology, we concur with Soreide et al that this mistake is bound to occur with series reporting large sample numbers. In cases where the cytodiagnosis is not consistent with clinical and other findings the patient should be reevaluated. The subsequent clinical course of the patient, however, is the best indicator of the benign or malignant nature of the disease.

Few complications have been reported after fine needle aspiration. Haemorrhage into the common bile duct ${ }^{5}$ and septicaemia related to the transhepatic cholangiography ${ }^{3}$ have been reported, but we have not encountered these complications, either in the present series or in a series of 285 examinations during the same period for patients with suspected lesions of liver or pancreas. Seeding of tumour along the needle track has been reported in six cases after aspiration biopsy of the pancreas. ${ }^{17-21}$ This exceedingly rare complication has not, however, been reported after aspiration biopsy of biliary tumours.

Cytodiagnosis of extrahepatic biliary strictures is a safe procedure, is not technically demanding, and has a high sensitivity and patient predictive value for positive cytology. It should be attempted in all such cases as it not only helps in the planning of further investigations but may allow confident use of palliative stenting and adjuvant treatment and save a fruitless laparotomy in cases considered unresectable on radiological grounds.

1 Ferrucci JT Jr, Wittenberg J, Mueller PR, et al. Diagnosis of abdominal malignancy by radiologic fine needle aspiration biopsy. AfR 1980; 134: 323-30.
2 Bernardino ME. Percutaneous biopsv. A $7 R$ 1984; 142: $41-5$. 3 Hall-Craggs MA, Lees WR. Fine needle aspiration biops: pancreatic and biliary tumors. A7R 1986; 147: 399-403.

+ Cope C, Marinelli DL, Weinstein JK. Transcatheter biopsy of lesions obstructing the bile ducts. Radiology 1988; 169:5556.

5 Kuroda C, Yoshioka H, Tokunaga K, et al. Fine needle aspiration biopsy via percutaneous transhepatic catheterization: techniques and clinical results. Gastrointest Radiol 1986; 11: 81-4.

6 Evander A, Ihse I, Lunderquist A, Tylen U, Akerman M. Percutaneous cytodiagnosis of carcinoma of the pancreas and bile duct. Ann Surg 1978; 188: 90-2

7 Cohan RH, Illescas FF, Braun SD, Newman GE, Reed Dunnick N. Fine needle aspiration biopsy in malignant obstructive jaundice. Gastrointest Radiol 1986; 11 : 145-50.

8 Schwerk WB, Durr HK, Schmit\%-Moormann P. Ultrasound guided fine needle biopsies in pancreatic and hepatic guided fine needle biopsies in pancreatic

9 Standfield NJ, Salisbury JR, Howard ER. Benign nontraumatic inflammatory strictures of the extrahepatic biliary s:stem. Br F Surg 1989; 76: 849-52.

10 Hadjis NS, Collier NA, Blumgart LH. Malignant masquerade at the hilum of the liver. Br $\mathcal{F}$ Surg 1985; 72:659-61.

11 Terblanche J, Saunders SJ, Louw JH. Prolonged palliation in carcinoma of the main hepatic duct junction. Surgery 1972; 71:720-31.

12 Leung JW, Sung JY, Chung SC, Chan KM. Enúoscopic scraping biopsy of malignant biliary strictures. (jastrointest Endosc 1989; 35: 65-6.

13 Mendex G Jr, Russell E, Levi JU, Koolpe H, Cohen M. Percutaneous brush biopsy and internal drainage of biliary tree through endoprosthesis. AfR 1980; 134: 653-9.

14 Osnes M, Serck-Hanssen A, Myren J. Endoscopic retrograde brush cytology (ERBC) of the biliary and pancreatic ducts. Scand F Gastroenterol 1975; 10: 829-3̈1.

15 Soreide O, Skaarland E, Pedersen OM, Larssen TB, Arnesio B. Fine needle biopsy of the pancreas: results of 204 routinely performed biopsies in 190 patients. World $\mathcal{F}$ Surg 1985; 9: 960-5.

16 Muro A, Mueller PR, Ferruci JT, Taft PD. Bile cytology: a routine addition to percutaneous biliary drainage. Radiology routine addition $1983 ; 149: 8+6-7$.

17 Caturelli E, Rapaccini GL, Anti M, Fabiano A, Fedeli G. Malignant seeding after fine-needle aspiration biopsy of the pancreas. Diagn Imaging Clin Med 1985; 54: 88-91

18 Ferruci JT Jr, Wittenberg J, Margolies MN, Carey RW Malignant seeding of the tract after thin needle aspiration biopsy. Radiologv 1979; 130: 3+5-6.

19 Rashleigh-Belcher HJC, Russell RCG, Lees WR. Cutaneous seeding of pancreatic carcinoma by fine needle aspiration biopsy. Br f Radiol 1986; 59: 182-3.

20 Smith FP, MacDonald JS, Schein PS, Ornit\% RD. Cutaneous seeding of pancreatic cancer by skinny-needle aspiration seeding of pancreatic cancer by skinn
biopsy. Arch Intern Med 1980; 140: 855 .

21 Bergenfeldt M, Genell S, Lindholm K, Ekberg O, Aspelin P. Needle tract seeding after percutaneous fine-needle biopsy of pancreatic cancer. Aita Chir Scand 1988; 154: 77-9. 